\title{
O sensível como agente da esfera pública: o uso da razão e emoção no debate online sobre a proposta de proibição do Funk
}

\section{Lo sensible como agente de la esfera pública: el uso de la razón y la emoción en el debate sobre la propuesta de prohibición del Funk}

\section{Sensitive as an agent of the public sphere: the use of reason and emotion in the debate on the proposed ban on Funk}

\author{
Ms. Lucas Arantes Zanetti $^{1}$ \\ Universidade Estadual Paulista (Brasil) \\ lucaszanetti66@gmail.com \\ Dra. Caroline Kraus Luvizotto ${ }^{2}$ \\ Universidade Estadual Paulista (Brasil) \\ caroline.luvizotto@unesp.br
}

Fecha de recepción: 22 de agosto de 2019 Fecha de recepción evaluador: 24 de agosto de 2019 Fecha de recepción corrección: 30 de agosto de 2019

\footnotetext{
${ }^{1}$ Jornalista, mestre em Comunicação pela Unesp - Universidade Estadual Paulista. Membro do Grupo de Pesquisa Comunicação Midiática e Movimentos Sociais - ComMov. ORCID: https://orcid.org/0000-00032019-8061

${ }^{2}$ Socióloga, doutora em Ciências Sociais. Docente do Programa de Pós-graduação em Comunicação da Unesp - Universidade Estadual Paulista. Líder do Grupo de Pesquisa Comunicação Midiática e Movimentos Sociais - ComMov. https://orcid.org/0000-0002-2132-4616
} 


\section{Resumo}

O fortalecimento de uma cultura democrática pressupõe a internalização de práticas deliberativas no cotidiano, garantidas pelo exercício do direito à livre circulação de ideias liberdade de expressão a partir do incentivo à participação e do fomento ao debate público. Em 22 de junho de 2017, a página do Senado Federal no Facebook consultou os cidadãos a respeito da Sugestão Legislativa no17 (SUG17/2017) que trata da "Criminalização do Funk como crime de saúde pública a criança, aos adolescentes e a família". A partir deste caso, foi realizado um estudo empírico sobre a circulação diferida e difusa de sentidos, produzidos em ambientes deliberativos online, em que razão e emoção se hibridizam na construção argumentativa dos sujeitos. Este estudo pretendeu analisar como ocorreu a construção argumentativa sobre a proposta de criminalização do Funk na página do Senado Federal no Facebook, tendo como foco a interação entre os usuários e a circulação de sentidos. Além da pesquisa bibliográfica exploratória sobre o tema, foi realizada a análise de 63 comentários de cidadãos a respeito da SUG17/2017 na página do Facebook do Senado Federal. O processo de levantamento de dados e sua avaliação revelam uma tendência ao uso de discursos híbridos, que se utilizam de razão e emoção em suas construções argumentativas. Ao final do estudo, foi possível compreender os sentidos, racionais e emocionais, utilizados para justificar posicionamentos sobre a proibição do Funk.

Palavras-chaves: Deliberação online; Razão; Emoção; Funk.

\section{Resumen}

El fortalecimiento de una cultura democrática presupone la internalización de las prácticas deliberativas en la vida cotidiana, garantizada por el ejercicio del derecho a la libre circulación de ideas, la libertad de expresión, alentando la participación y fomentando el debate público. El 22 de junio de 2017, la página de Facebook del Senado Federal consultó a los ciudadanos sobre la Sugerencia Legislativa No. 17 (SUG17 / 2017) que trata sobre la "Criminalización del Funk como un delito de salud pública para niños, adolescentes y familias". A partir de este caso, se realizó un estudio empírico sobre la circulación diferida y difusa de significados, producidos en entornos deliberativos en línea, en los que la razón y la emoción se hibridan en la construcción argumentativa de los sujetos. Este estudio tuvo como objetivo analizar cómo se produjo la construcción argumentativa de la propuesta de criminalización de Funk en la página de Facebook del Senado Federal, centrándose en la interacción entre los usuarios y la circulación de significados. Además de la investigación bibliográfica exploratoria sobre el tema, analizamos 63 comentarios de ciudadanos sobre SUG17 / 2017 en la página de Facebook del Senado Federal. El proceso de recolección de datos y su evaluación revelan una tendencia a usar discursos híbridos, que usan la razón y la emoción en sus construcciones argumentativas. Al final del estudio, fue posible comprender los sentidos, racionales y emocionales, utilizados para justificar posiciones sobre la prohibición del Funk. 
Palabras clave: Deliberación en línea; Razón; Emoción; Funk.

\begin{abstract}
The strengthening of a democratic culture presupposes the internalization of deliberative practices in daily life, guaranteed by the exercise of the right to the free circulation of ideas, freedom of expression, by encouraging participation and fostering public debate. On June 22, 2017, the Federal Senate Facebook page consulted citizens regarding Legislative Suggestion No. 17 (SUG17 / 2017) which deals with the "Criminalization of Funk as a Public Health Crime for Children, Adolescents and Family". From this case, an empirical study was performed on the deferred and diffuse circulation of meanings, produced in deliberative online environments, in which reason and emotion hybridize in the argumentative construction of the subjects. This study aimed to analyze how the argumentative construction on Funk's criminalization proposal occurred on the Federal Senate Facebook page, focusing on the interaction between users and the circulation of meanings. In addition to the exploratory bibliographic research on the subject, we analyzed 63 comments from citizens about SUG17 / 2017 on the Facebook page of the Federal Senate. The data collection process and its evaluation reveal a tendency to use hybrid discourses, which use reason and emotion in their argumentative constructions. At the end of the study, it was possible to understand the senses, rational and emotional, used to justify positions on the prohibition of Funk.
\end{abstract}

Keywords: Online deliberation; Reason; Emotion; Funk.

\title{
Introdução
}

O campo de estudo que se dedica a investigar as relações entre mídia, deliberação e esfera pública é consolidado como chave de compreensão de uma série de dinâmicas sociais inerentes às sociedades contemporâneas e necessárias ao fortalecimento das democracias. Dentre essas dinâmicas - que vão desde mecanismos de participação e interação política, modelos de democracia deliberativa, os processos de troca argumentativa e negociação de sentidos que caracterizam o debate público e formas de constituição da opinião pública - existem uma infinidade de objetos, teorias e metodologias a serem exploradas pelo viés científico. Entretanto, ainda que este campo seja amplo e possua aportes teóricos abrangentes e construídos ao longo de décadas de pesquisas, as análises empíricas ainda são pouco exploradas pelas pesquisas (Habermas, 2008; Maia et al. 2017; Marques, 2008).

O fortalecimento de uma cultura democrática pressupõe a internalização de práticas deliberativas no cotidiano, garantidas pelo exercício do direito à livre circulação de ideias liberdade de expressão a partir do incentivo à participação e do fomento ao debate público. Pressupõe, ainda, espaços de trocas entre sujeitos diversos que compartilham espaços comuns ainda que não partilhem de mesma identidade ou cultura, sendo que soluções devem ser encontradas dentro de negociações respaldadas pela inclusão democrática dos sujeitos minoritários (Silveirinha, 2005). Nesse cenário, a internet e as redes sociais digitais surgem como espaço possível para manifestações 
políticas e ações que aproximam Estado e cidadão. Este é o contexto em que se enquadra o presente artigo.

Em 22 de junho de 2017, a página do Senado Federal no Facebook consultou os internautas a respeito da Sugestão Legislativa $n^{\circ} 17$ (SUG17/2017) que trata da "Criminalização do Funk como crime de saúde pública a criança, aos adolescentes e a família". A sugestão, de autoria de um cidadão, conseguiu reunir o apoio necessário para a discussão da proposta no Senado. A postagem em questão abriu o debate público para questões como identidade brasileira, cultura de elite e da periferia, liberdade de expressão e censura, o impacto da música na formação de crianças e adolescentes, além dos mais variados temas, obtendo, até junho de 2019, um total de 52 mil reações, 24 mil compartilhamentos e 28 mil comentários na rede social.

O Portal do e-Cidadania, vinculado ao Senado serve como suporte para que qualquer cidadão proponha projetos e alterações em leis. Caso a proposição tenha 20 mil assinaturas em apoio, no prazo de 120 dias, ela se torna uma Sugestão Legislativa e deverá obrigatoriamente ser discutida entre os senadores. Além da possibilidade de propor e alterar leis, o Portal promove a consulta pública dos projetos de lei que tramitam no Senado, com o objetivo de aproximar os cidadãos da política em processos participativos e deliberativos. Por meio da página do Facebook, o Senado convida os cidadãos a participarem do debate público e a interação entre os cidadãos ocorre nos comentários da rede social.

A Comissão de Direitos Humanos e Legislação Participativa do Senado (CDH) indicou o Senador Romário (PODE/RJ) para conduzir e relatar a discussão. Foram convidados artistas do Funk, uma antropóloga, uma promotora de eventos relacionados ao gênero musical para debaterem a proposta junto ao Senado e ao seu proponente.

O resultado da consulta pública sobre a SUG17/2017 que pretendia transformar o estilo musical em crime recebeu 52.858 votos a favor e 38.477 votos contraii. Em 20 de setembro de 2017, a Comissão de Direitos Humanos e Legislação Participativa realizou sua $67^{\mathrm{a}}$ Reunião extraordinária e aprovou o relatório do Senador Romário, que passou a constituir o Parecer da CDH, pela rejeição da Sugestão Legislativa, que se encontra arquivada.

A partir deste caso, foi realizado um estudo empírico sobre a circulação diferida e difusa de sentidos - próprios da sociedade midiatizada, como assinala Braga (2006) produzidos em ambientes deliberativos online, em que razão e emoção se hibridizam na construção argumentativa dos sujeitos. Este estudo pretendeu analisar como ocorreu a construção argumentativa sobre a proposta de criminalização do Funk na página do Senado Federal, tendo como foco a interação entre os cidadãos e a circulação de sentidos.

O Funk enquanto prática estético-cultural localizada, em grande parte, em ambientes de pobres e periféricos, é alvo do histórico preconceito racial e de classe existente no Brasil (Mizrahi, 2010). O sentimento negativo em relação ao diferente, a negação da identidade do outro (Bandeira \& Batista, 2002) também são formas sensíveis 
que não estão fora do contexto da esfera pública. Ao causar estranhamento e tensões identitárias com viés racial e de classe, o caso da SUG17/2017 torna-se ilustração para questões sensíveis na esfera pública, tanto pela questão performática, artística e a estética do funk quanto pela forma que os sentidos sobre sua criminalização circulam na deliberação on-line.

O Facebook, por ser uma das redes sociais mais utilizadas no Brasil, e a página oficial do Senado por ser um canal de comunicação direto entre o centro e a periferia do processo de tomada de decisão política, são ferramentas que interessam os estudos em deliberação on-line, na medida em que possuem potencial de instigar e estimular o debate público. São arenas de ampla circulação de sentidos e amplo apelo emocional nas interações. Não obstante, também possuem uma série de problemas que serão discutidos no decorrer deste artigo.

O texto se divide em três partes: inicialmente, discute-se o papel da emoção em ambientes deliberativos, destacando a indissociabilidade entre razão e emoção no debate público. Na sequência, propõe-se uma reflexão sobre a relação entre midiatização, circulação de sentidos e o Funk. Por fim, apresenta-se a análise de 63 comentários de usuários na publicação do Senado Federal no Facebook a respeito da SUG17/2017, por meio de classificação e categorização dos comentários, conforme a metodologia proposta por Sampaio et al. (2012) e também a partir do Discourse Quality Index (DQI), índice que analisa a qualidade da deliberação. Pretende-se, com isso, compreender os sentidos - racionais e emocionais - utilizados para justificar posicionamentos sobre a proibição de um gênero musical periférico.

\section{Além da razão instrumental: o sensível e a arte nos processos deliberativos}

De acordo com Marques (2009), a comunicação nas práticas deliberativas vai além do processo midiático. Ela se configura, também, como um exercício de movimento em direção ao outro, uma vez que podemos considerar a deliberação como um processo no qual o indivíduo busca argumentos para convencer outros indivíduos do grupo a chegarem na melhor decisão para o bem comum.

A ideia de ambientes deliberativos informais ou ambientes de conversação, levam em conta as trocas que acontecem no cotidiano como elementos que se somam para compor o espaço público e a esfera pública plural. O cotidiano é responsável por uma série de trocas argumentativas, produção de sentidos e criação de justificativas que sustentam ideias e formam opiniões bem embasadas (Maia, 2008). Esses espaços passam a chamar atenção por sua capacidade de formação cidadã ao oferecer intercâmbios de conhecimentos e preparações para que a deliberação institucional ocorra de forma satisfatória de forma a difundir consciência democrática (Maia; et al., 2017). A premissa de que o cotidiano é composto por ambientes ricos para a formação de relações que refinam a capacidade deliberativa dos cidadãos a partir de recursos discursivos é necessária para a compreensão de expressões democráticas complexas, que se 
caracterizam pela ampla quantidade de informações, perspectivas e ideias que circulam diariamente e que dão sentido aos acontecimentos políticos, sociais e econômicos.

Numa perspectiva mais ampla, Bohman (2009), compreende a deliberação como um processo múltiplo, constituído de inúmeras esferas, além da esfera dialógica entre os indivíduos, uma vez que este processo é influenciado também pelos meios de comunicação. Para o autor, a cidadania confere igual direito de expressão e o sucesso do processo de deliberação reside no reconhecimento do outro e da legitimidade de seu argumento.

Habermas (1997) canaliza seus esforços no desenvolvimento de um modelo da democracia deliberativa com enfoque na ética do discurso, cujo imperativo seria a troca pública de razões por meio da interação entre instituições, indivíduos e grupos sociais em diferentes níveis e arenas da sociedade civil.

O desenvolvimento da ideia de "circulação do poder político" (Habermas, 1997, p.73), gerado a partir do poder comunicativo entre os atores sociais, indica que a esfera pública política deve ser um ambiente de conexão entre cidadãos, organizações e movimentos sociais com as instituições formais que possuem poder de decisão. Para Habermas (1997), é por meio do debate público racional que a política ganha legitimidade nas sociedades democráticas.

Ao estabelecer sua teoria da ação comunicativa, da troca pública de argumentos e da justificação lógica das ações e opiniões como modelo de democracia deliberativa, Habermas acaba tendo um viés racionalista que tem sido alvo de críticas por parte de autores que enxergam a emoção, a paixão, a retórica, o sensível e a estética como fundamentais no ato político (Sodré, 2006; Mansbridge, 1999; Maia, 2012).

Para Sodré (2006, p. 49), Habermas se atém a uma "pragmática da linguagem" e a uma "razão iluminista" ao buscar estabelecer "condições para a compreensão mútua", por isso "prescinde de qualquer apelo à dimensão do sensível". A crítica de Sodré ao modelo habermasiano advém da ideia de que a eficácia da razão depende da dimensão estética e sensível e que, em última instância, "a própria razão emerge do afeto" (Sodré, 2006, p. 41). A razão seria induzida a partir dimensão afetiva dos sujeitos, visto que as paixões levariam a juízos anteriores a própria reflexão. Dessa forma, a própria dimensão do real só é possível de ser alcançada a partir das emoções, pois é por meio delas que se atinge o "sentido da consciência" (Sodré, 2006, p. 53). Portanto, a análise de Sodré, mesmo que não descarte a razão no ato de compreensão do mundo, a coloca em segundo plano no processo de produção de sentidos e compreensão do real.

A ideia de "partilha do sensível" de Racière (2009) leva a intersecção entre estética e política a patamares ainda mais complexos. Sob a perspectiva da política como forma de experiência, "a partilha do sensível faz ver quem pode tomar parte do comum em função daquilo que faz, do tempo e do espaço em que essa atividade se exerce" (Rancière, 2009, p.16). Ou seja, ao admitimos a relevância do sensível, da estética e da emoção para uma esfera pública política de caráter deliberativo, é preciso compreender 
de que forma e quais as condições que os sujeitos podem tomar parte, interagir e produzir sentido a partir da circulação discursiva inerente a este processo.

Para isso, na lógica da intersubjetividade - que em Habermas seria um processo racional de troca argumentativa e de justificação pública (Sodré, 2006) - é preciso levar em conta a diversidade, a retórica, a sensibilidade, a empatia, as histórias pessoais e de forma inclusiva. As práticas artísticas, passam, sob esta ótica a serem vistas como formas de "inscrição" do sujeito na comunidade, visto que por meio dela a barreira de questões práticas como a "ocupação" e o "tempo" dos sujeitos que impedem o ato da participação seria, de certa forma, quebrada. Na perspectiva aqui proposta, tais práticas passam a serem vistas como úteis à esfera pública.

Os exemplos usados por Racière (2009, p.17) para ilustrar a questão é o teatro e a escrita, que seriam "atividades públicas" que embaralham a partilha das "atividades e dos espaços" que diferencia os homens, já que estes possuem seu lugar na política demarcado por essas "ocupações" que definem o tempo de dedicação à atividade política e "competências e incompetências para o comum" (Racière, 2009, p.16) A estética oriunda das práticas artísticas de uma comunidade, seria o reflexo dela própria, de suas estruturas sociais e movimentação. Neste sentido, a arte de uma comunidade, a produção cultural também revela aspectos da visão de bem comum e troca de sentidos e argumentos, não de forma racional como defende Habermas (1997), mas sob forma sensível.

Chantal Mouffe (apud Maia, 2012, p.19), argumenta que a democracia deliberativa em Habermas "elimina as paixões da esfera do público e dos modelos estéticos-afetivos da comunicação". Maia (2012, p. 19), defende que "a emoção e outras formas de comunicação são importantes para a deliberação" e que elas não são "incompatíveis com a teoria habermasiana da racionalidade". Dessa forma, compreendese que é possível ampliar o conceito de esfera pública para que se leve em conta no processo deliberativo elementos sensíveis e não apenas argumentos racionais e justificação pública. Iris Young (2000) também defende a ideia afetiva e busca trazer à perspectiva deliberacionista a dimensão sensível, como a narrativa pessoal e a retórica.

É verdade que, quando se adota essa perspectiva, a ideia de democracia deliberativa se torna mais complexa no que concerne a interação e ao agir comunicativo característicos do processo deliberativo. No entanto, adverte Mendonça (2011) que a deliberação não se deve confundir deliberação com comunicação, pois ela ainda deve ser mantida como ambiente agente da reflexão de forma não coercitiva e de forma a conectar o particular, o sensível e o estético a um princípio geral.

Para Mizrahi (2010, p. 250), o Funk enquanto prática artística da periferia que circula de forma informal em sua produção e difusão, se apresenta como forma da "subversão estética", a medida em que sua estética hiper-realista está em "conexão direta com o que a vida produz". É, portanto, como afirma Rancière (2009), reflexo da própria estrutura social com a qual foi produzida. Uma estrutura social de periferia que carrega em si o preconceito de classe e de raça. O debate público gerado a partir da estética do 
Funk, a partir da tentativa de criminalização, pode ser entendido, portanto, como elemento de uma esfera pública que envolve um grande aspecto sensível e emocional.

\section{Midiatização, circulação de sentidos e o Funk}

De acordo com Seridório e Luvizotto (2017, p. 84), do ponto de vista comunicacional, "a deliberação envolve processos comunicativos em dois âmbitos: a própria comunicação interpessoal; e o papel dos meios de comunicação na formação do arsenal argumentativo dos participantes". Quando essa discussão pública ocorre no ciberespaço, na internet, as autoras indicam um terceiro âmbito: a comunicação midiatizada. "Então, além da rede formada pelo diálogo, o debate de cunho deliberativo que ocorre na internet tem status de comunicação midiatizada, possuindo maiores chances de impactar a opinião pública" (Seridório \& Luvizotto, 2017, p. 84).

A partir das contribuições dos estudos em midiatização, a mídia passa a ser vista não apenas como um instrumento da esfera pública no sentido de oferecer informações e razões aos sujeitos para que formulem suas opiniões, mas sim como um elemento estruturante da própria relação entre Estado e sociedade. A ideia é que a comunicação midiática não exerce poder direto na sociedade, mas sim, colabora na circulação de discursos cujos sentidos produzidos são diferidos e difusos (Braga, 2006).

Nesse sentido, as práticas políticas têm na comunicação um de seus elementos estruturantes e integra o que Barros (2012, p. 85) chama de "dimensão contemporânea da esfera pública". Para o autor, isso se justifica porque "a sociedade contemporânea está estruturada em uma lógica midiática que dá sustentação à consciência e à construção de identidades do indivíduo e do grupo" (p. 85). Seguindo a mesma linha, Guareschi (2007, p. 8) afirma que "não há instância de nossa sociedade que não tenha uma relação profunda com a mídia e que não esteja intrinsecamente contaminada por ela", de forma que "a comunicação constrói, hoje, o novo ambiente social”.

A ótica da sociedade midiatizada dá um tom mais complexo para os estudos entre mídia e esfera pública, já que para essa vertente é preciso ir além da compreensão que o processo comunicativo se limita ao clássico esquema emissão-recepção (Braga, 2006). Braga considera que esta visão é restritiva e parte de um dualismo entre mídia e sociedade, em que a primeira teria um papel ativo e a segunda uma posição inerte no processo. Como alternativa a esta perspectiva, o autor propõe uma visão que considere a comunicação com um processo de interação, levando em conta o papel dos indivíduos e grupos frente aos conteúdos midiáticos e suas significações no ambiente social.

Assim, o processo comunicativo passa a ser analisado em um contexto maior, levando sua complexidade e o que Braga (2006) chama de sistema de resposta social. Essa ideia, por sua vez, considera que "os sentidos midiaticamente produzidos chegam a sociedade e passam a circular entre pessoas, grupos e instituições, impregnando e parcialmente direcionando a cultura" (Braga, 2006, p. 27). 
Partindo desta perspectiva, consideramos que os sentidos produzidos em relação ao Funk no sistema de circulação dos sentidos são os mais diversos. No entanto, não é desconsiderada a perspectiva de que a mídia contribui para a construção de um imaginário popular sobre os mais diversos temas. No processo de circulação de sentidos midiáticos sobre o Funk, que se inicia intensamente na década de 1990, a mídia desempenha, contraditoriamente, tanto um papel de estigmatização quanto de promoção mercadológica do gênero musical (Freire Filho \& Herschmann, 2003).

Os mais renomados jornais e revistas como O Globo, Folha de S. Paulo, Jornal do Brasil, Revista IstoÉ e Revista Veja, já fizeram matérias críticas à estética e ao conteúdo do Funk em diversos momentos. O próprio conhecimento público do Funk a partir de um evento em 1992, quando jovens reproduziram na praia do Arpoador (RJ), durante o dia, os rituais de luta que aconteciam nos bailes funk. $O$ fato foi noticiado como "arrastão" pela imprensa nacional e internacional, associando o gênero musical à criminalidade desde seu início (Lopes, 2011; Facina, 2009).

Apesar de ocorrer uma histeria anti-funk por parte da imprensa e por parte da classe média nos anos 90, o Funk se consolidou enquanto gênero musical no final dos anos 1990, influenciando a moda e a indústria do entretenimento. Claro que, a partir disso, diversas vertentes e formas de Funk passaram a existir, algumas com apelos mais mercadológicos e outras que conservaram uma certa originalidade do estilo (Freire Filho \& Herschmann, 2003).

Tais fatos mostram que, apesar do sucesso na indústria do entretenimento e da influência do Funk na cultura brasileira contemporânea, os sentidos que circulam sobre o gênero desde sua popularização possuem conotação negativa. Entretanto, conforme aponta Vianna (1990, pp. 249-250), os produtos relacionados ao Funk são muito diversos e "podem ser consumidos de maneiras diferentes por grupos sociais diferentes e que podem circular (até mesmo intencionalmente) por caminhos pouco convencionais, independentes dos grandes meios de comunicação de massa".

Atualmente, dois grandes debates que se observa sobre o Funk na sociedade estão relacionados ao fato de o gênero ser ou não cultura e sobre a sua criminalização (Facina, 2009). A ideia de criminalização não é nova, como propõe Facina (2009). Para a autora, a criminalização é um sentido atribuído ao movimento desde se popularizou e deixou de estar restrito às periferias, tanto por parte dos conteúdos midiáticos quanto pela própria ação do Estado. O poder público, explica Facina (2009), não raramente persegue e fecha bailes funk Brasil a fora sob a justificativa de que há ligação do gênero com o tráfico de drogas e a violência. 


\section{Metodologia}

O presente artigo se estrutura a partir da metodologia proposta por Sampaio et al. (2012) e também a partir do Discourse Quality Index (DQI) (Steenbergen et al., 2003 apud Mendonça \& Pereira, 2011), metodologias complementares e com o objetivo de avaliar a deliberação por meio de critérios e classificações discursivas.

No entanto, alguns critérios foram acrescentados para abranger a questão afetiva e emocional, a qual este artigo se propõe a investigar. Segundo Mendonça e Pereira (2011, p. 5), os estudiosos que se desdobram a aprimorar metodologias que avaliem a deliberação já reconhecem a "nova literatura teórica de deliberação, mais atenta à retórica, às narrativas pessoais, às negociações políticas, ao auto interesse e às disputas de poder".

Dessa forma, a partir do conteúdo de 63 comentários de usuários, publicados via Facebook na página do Senado Federal e escolhidos aleatoriamente a respeito da SUG17/2017, identificou-se os argumentos mais recorrentes a respeito da proposta de criminalização do Funk. Na seleção, foram excluídos comentários com menos de 1 linha de resposta, comentários em forma de imagem, foto, emoticon ou gif e comentários que não estão se propuseram à argumentação, como marcação de amigos.

Em seguida, os comentários foram classificados como sendo de cunho estritamente racional, estritamente emocional ou híbridos, ou seja, que possuem elementos racionais e emocionais em sua constituição.

Foram considerados comentários de ordem estritamente racional aqueles que, além de não terem nenhum tipo apelo ou referência ao uso da emoção, cumprem os mais recorrentes critérios de deliberação on-line também descritos no DQI. São eles:

Justificação: justificativa lógica, racional e moral do argumento na defesa de um ponto de vista (Sampaio et. al., 2012).

Reflexibilidade: consiste na interação, diálogo, troca e consideração da perspectiva alheia na construção do argumento. (Sampaio et. al., 2012).

Informação: busca e atribuição de fontes que justifiquem e embasem ideias ou argumentos. (Sampaio et. al., 2012).

Optou-se por apenas três categorias devido ao fato de que a avaliação da qualidade racional do debate não é o foco do presente artigo. Pretende-se mostrar o contraste e a mistura entre razão e emoção e a frequência de sentidos e argumentos que circulam sobre uma prática artística e cultural brasileira.

Os critérios para argumentos de ordem estritamente emocional, além de não conter nenhuma referência ou apelo a base racional, foram estabelecidos base nas pesquisas de Maia (2012) sobre a emoção, retórica e narrativas pessoais na esfera pública, sendo eles: 
Narrativas pessoais: o uso de histórias pessoais, vivências, narrativas e testemunhos de ordem particular (Maia, 2012).

Retórica plebiscitária e ironia: retórica plebiscitária, ao contrário da "retórica deliberativa", é uma forma de retórica que emprega o discurso com a finalidade de "vencer" e desprovida de informação e que, portanto, não é interessante a deliberação (Maia, 2012, p. 23). Acrescentamos a este conceito o uso da ironia também desprovida de informação e justificação lógica e consideramos dessa forma os discursos que causam impacto por meio de sua forma, de seu apelo e recursos linguísticos que buscam convencer as pessoas sem apelo racional.

Preconceito: esta categoria foi acrescentada por nós ao notarmos vestígios de discursos preconceituosos e de ódio contra o Funk, sua origem periférica e seus apreciadores. São argumentos que atacam os funkeiros, a periferia por meio de xenofobia, racismo ou ódio de classe.

Considerou-se discursos híbridos aqueles em que é possível perceber uma mistura entre elementos do que foi considerado racional e do que foi considerado emocional ou sensível.

\section{Resultados e Discussão}

Dos 63 comentários analisados obteve-se os seguintes resultados:

\begin{tabular}{|c|c|}
\hline Argumento estritamente racional & 16 \\
\hline Argumento estritamente emocional & 14 \\
\hline Híbridos & 33 \\
\hline Total & 63 \\
\hline
\end{tabular}

De acordo com os critérios para comentários racionais e emocionais adotados, obteve-se o seguinte resultado iii (foi considerado mais de uma forma de argumentação no mesmo discurso quando necessário):

\begin{tabular}{|c|c|}
\hline Racionais (total) & 47 \\
\hline Justificação & 35 \\
\hline Reflexibilidade & 5 \\
\hline
\end{tabular}




\begin{tabular}{|c|c|}
\hline Emocionais (total) & 46 \\
\hline Narrativas pessoais & 13 \\
\hline Retórica plebiscitária e ironia & 17 \\
\hline Preconceito & 16 \\
\hline
\end{tabular}

Também se constatou a seguinte frequência de justificativas discursivas sobre a criminalização ou não do Funk ${ }^{\text {iv. }}$

Favoráveis à proibição:

\begin{tabular}{|c|c|}
\hline Argumento & $\begin{array}{c}\text { Frequência (número de discursos } \\
\text { que o argumento apareceu) }\end{array}$ \\
\hline Funk faz apologia (violência, drogas, sexo). & 8 \\
\hline Argumento preconceituoso/deboche/ataques e xingamentos & 8 \\
\hline Funk não é cultura/Funk não é música, pode ser proibido & 7 \\
\hline Funk é machista/sexista/desrespeita as mulheres & 5 \\
\hline Funk promove sexualização de crianças e adolescentes & 3 \\
\hline Funk é um desrespeito a moral e bons costumes & \\
\hline Funk envergonha o país & \\
\hline
\end{tabular}

\section{Contrários à proibição:}




\begin{tabular}{|c|c|}
\hline Argumento & $\begin{array}{c}\text { Frequência (número de discursos que o } \\
\text { argumento apareceu) }\end{array}$ \\
\hline Funk é cultura, não se pode proibir & 15 \\
\hline Proibir o Funk é censura & 11 \\
\hline $\begin{array}{c}\text { Outros gêneros musicais fazem apologia (às } \\
\text { drogas, sexo e violência) mas não se cogita } \\
\text { proibição }\end{array}$ & 8 \\
\hline $\begin{array}{l}\text { O Funk não é causa do crime e da violência/Os } \\
\text { crimes derivados devem ser punidos não o Funk } \\
\text { em si }\end{array}$ & 7 \\
\hline $\begin{array}{l}\text { Funk representa parte da população } \\
\text { brasielira/Funk reflete a sociedade }\end{array}$ & 5 \\
\hline $\begin{array}{c}\text { Não cabe ao legislativo decidir/o Estado tem } \\
\text { coisas mais importantes a tratar }\end{array}$ & 4 \\
\hline A proposta é inconstitucional & 2 \\
\hline Funk gera renda à comunidade e aos artistas & 2 \\
\hline $\begin{array}{l}\text { Argumento preconceituoso/deboche/ataques e } \\
\text { xingamentos }\end{array}$ & 2 \\
\hline A proibição do Funk é preconceituosa & 2 \\
\hline
\end{tabular}

O processo de levantamento de dados e sua avaliação revelam uma tendência maior ao uso de discursos híbridos, que se utilizam de razão e emoção em suas construções argumentativas. A discussão sobre a SUG17/2017 envolve questões de classe, raça e gênero, por isso revela um grande tensionamento entre as opiniões, o que, junto com a linguagem e o anonimato característicos das redes sociais, sugere-se como consequência da elevada quantidade de recursos emocionais nos argumentos.

A estética do Funk, gênero que tem origem a partir de uma classe marginalizada e moradora das periferias, é frequentemente associada à criminalidade e a violência. Como ficou claro ao decorrer do artigo, isso é algo que tem origem na própria construção do imaginário sobre o funk na sociedade. Rancière defende $(2009$, p.17) que a estética deve ser vista "como formas de visibilidade das práticas da arte, do lugar que ocupam, do 
que fazem no que diz respeito ao comum”. O Funk enquanto produto estético levanta discussões mais profundas do que a prática artística em si. Levanta discussões sobre a sociedade, cultura, política, legislação, opressão, classes sociais, identidade, questões de gênero e raça e violência que extrapolam sua própria estética e seu próprio conteúdo.

A partir disso, a estética e as práticas culturais podem servir para incendiar a esfera pública sobre as mais variadas óticas e perspectivas. Como defende Sodré (2006), é o sensível dando origem a razão. É a identificação, o incômodo, a satisfação, a indignação, a necessidade de contar uma história que mobiliza os sujeitos a participarem e a pensarem em razões e justificações para seus posicionamentos. E é por isso que a maior parte dos discursos são híbridos e mesclam estratégias racionais e sensíveis.

Com relação à midiatização, sugere-se que este é um conceito muito mais amplo, de difícil aplicação em uma pesquisa empírica como esta, como o próprio Braga (2006) defende. No entanto, a perspectiva da midiatização auxilia no sentido de encarar o estudo com outro viés, que é o da mídia sendo um elemento que estrutura a sociedade e as relações. Os sentidos circulam de forma diferida e difusa. Muitos discursos, argumentos e justificativas são reproduções das mesmas razões atribuídas ao Funk desde sua origem no que diz respeito a associação do gênero com a criminalidade e violência - que no fundo, como defende Facina (2009) é uma associação racista e elitista. Não se discute se outros gêneros musicais são ou não cultura como se fazem com o Funk e muito desse reforço ocorre de forma diferida e difusa.

Destaca-se o fato da grande quantidade de preconceito, ódio e formas emocionais que prejudicam o andamento do debate. Ataques pessoais, xingamentos, o uso extremo e prejudicial do particular e da experiência pessoal foram fatores que se revelaram desgastantes e são formas emocionais extremamente prejudiciais a esfera pública e a democracia. Isso pode ser observado, por exemplo, em comentários que mencionam desgastes e embates ocorridos em função de alguém estar escutando Funk em volume muito alto, ou então à problemas ocorridos em decorrência de bailes funk. Episódios particulares, mas que foram levados ao debate em caráter generalizador, sugerindo um problema que afeta todas as pessoas que entram em contato, contra a sua vontade, com o estilo musical.

\section{Considerações finais}

Tanto a dimensão sensível quanto a perspectiva da sociedade em midiatização se apresentam como desafios nos estudos de mídia, esfera pública e deliberação. Não foi de pretensão deste artigo, entretanto, delimitar conceitualmente as intersecções possíveis. A ideia foi, a partir da colaboração de autores que criticam a racionalidade habermasiana na teoria deliberativa, demonstrar que existe uma dimensão sensível no processo de troca argumentativa, que este processo se torna diferido e difuso pois vivemos em uma sociedade midiatizada e que as artes podem servir como forma de incendiar o debate na esfera pública. 
Reforça-se a importância de considerar questões estéticas, artísticas e culturais como formas legítimas de constituição da esfera pública. Tanto como agente gerador de reflexão, mobilizador e provedor de discussões quanto a compreensão que a dimensão sensível é uma das maneiras que despertam o engajamento, a participação e o interesse em questões públicas e políticas.

A complexidade que se cria ao se levar em conta tais fatores como legítimos à esfera pública e a teoria da democracia deliberativa é característica da própria sociedade. Não é possível definir o quanto as questões emocionais e sensíveis contribuem para o fortalecimento da democracia e para o bem comum. Mas é fato que estas questões existem e devem ser levadas em conta nas análises que se fazem destes processos.

A análise dos comentários sugere que há longos passos a serem percorridos para que se possa ter uma esfera pública eficiente, com justificação, reflexibilidade e informação no Brasil. No entanto, eles revelam que a quantidade de instrumentos discursivos racionais, emocionais e híbridos são bastante equilibrados. Não podemos perder de vista o quão recente é nossa democracia e, principalmente o quão recente é o fenômeno da internet e das redes sociais. Por isso, estima-se que o exercício democrático, por vezes penoso, poderá criar bons frutos no futuro.

Para contribuir para a democratização das informações de interesse público, acredita-se que, somadas a outros formatos, as redes sociais online devem fazer parte de um escopo de instrumentos comunicacionais que devem ser utilizados para o exercício da Comunicação Pública na promoção da cidadania, dadas as peculiaridades que as redes sociais têm assumido, especialmente no Brasil: tornaram-se parte integrante do cotidiano, tanto no público, quanto no privado.

\section{Referências Bibliográficas}

Bandeira, Lourdes, \& Batista, Analía Soria. (2002). Preconceito e discriminação como expressões de violência. Estudos feministas. p. 119-141.

Barros, Laan Mendes. (2012). Recepção, mediação e midiatização: conexões entre teorias europeias e latino-americanas. Mediação e Midiatização. Salvador: EDUFBA.

Bohman, James. (2009). O que é a deliberação pública? Uma abordagem dialógica. Em Ângela Cristina Salgueiro Marques (org. e trad.). A deliberação pública e suas dimensões sociais, políticas e comunicativas. Belo Horizonte: Autêntica.

Braga, José Luiz. (2006). A sociedade enfrenta sua mídia: dispositivos sociais de crítica midiática. São Paulo: Paulus.

Facina, Adriana. (2009). "Não Me Bate Doutor": Funk e criminalização da pobreza. $V$ Encontro de Estudos Multidisciplinares em Cultura. Faculdade de Comunicação, Salvador, Bahia. 
Freire Filho, João; Herschmann, Micael. (2003). Funk carioca: entre a condenação e a aclamação na mídia. Revista ECO-Pós, p. 60-72.

Guareschi, Pedrinho Arcides. (2007). Mídia e democracia: o quarto versus o quinto poder. Revista Debates. Porto alegre: v. 1, n. 1, p. 6.

Habermas, Jürgen. (1997). Direito e Democracia I e II. Rio de Janeiro: Tempo Brasileiro.

Habermas, Jurgen. (2008). Comunicação política na sociedade mediática: o impacto da teoria normativa na pesquisa empírica. Líbero, ano XI, no. 21, p. 09-20.

Maia, Rousiley. C. M. (2012). Emoção, retórica e histórias pessoais na esfera pública. Em Murilo Cesar Soares (org). Mídia e Cidadania. São Paulo: Editora Unesp.

Maia, Rousiley. (2008). Mídia e deliberação. Rio de Janeiro: FGV Editora.

Maia, Rousiley C. M. et al. (2017). Conversação e deliberação sobre questões sensíveis: um estudo sobre o uso das razões que circulam nos media. Galáxia. n. 34, p. 55-72.

Marques, Angela Cristina S. (2008). Os meios de comunicação na esfera pública: novas perspectivas para articulações entre arenas e atores. Libero, ano XI, no. 21, p. 23-36.

Marques, Ângela Cristina S. (2009). As intersecções entre o processo comunicativo e a deliberação pública. Em Ângela Cristina S. Marques (Org. e trad.). A deliberação pública e suas dimensões políticas comunicativas: textos fundamentais. Belo Horizonte: Autêntica Editora, p. 11-28.

Mansbridge, J. (1999). Everyday Talk in Deliberative System. Em Stephen Macedo (ed.). Deliberative Politics. NY: Oxford University Press, p. 211-239.

Mendonça, Ricardo Fabrino. (2011). Reconhecimento e (qual?) deliberação. Opinião Pública, v. 17, n. 1, p. 206-227.

Mendonça, Ricardo Fabrino, \& Pereira, Marcus Abílio. (2011). Democracia digital e deliberação online: um estudo de caso sobre o VotenaWeb. Congresso Latino Americano de Opinião Pública-Wapor. Belo Horizonte, p. 1-37.

Mizrahi, Mylene. (2010). A estética funk carioca: criação e conectividade em Mr. Catra. Rio de Janeiro: 7Letras.

Sampaio, Rafael Cardoso, et. al. (2012). Como avaliar a deliberação online?: um mapeamento de critérios relevantes. Opinião Pública, v. 18, n. 2, p. 470-489.

Seridório, D. F.; Luvizotto, C. K. (2017). Internet como espaço de deliberação e participação política. Comunicação \& Sociedade. São Bernardo do Campo, v. 39, n. 3, p. 79-110, set./dez.

Silveirinha, Maria João. (2005). Democracia deliberativa e reconhecimento: repensar o espaço público. Em João Carlos Correia (org). Comunicação e Política. Universidade da Beira Interior, p. 147-180 
Sodré, Muniz. (2006). As estratégias sensíveis: afeto, mídia e política. Petrópolis: Vozes.

Rancière, Jacques. (2009). A partilha do sensível. São Paulo: Editora, v. 34.

Vianna, H. (1990). Funk e cultura popular carioca. Revista Estudos HistóRicos, 3(6), p. 244-253. Recuperado

de http://bibliotecadigital.fgv.br/ojs/index.php/reh/article/view/2304. Acesso em $31 / 08 / 2019$.

Young, Iris Marion. (1996). Communication and the other: Beyond deliberative democracy. Em Seyla Benhabib (org). Democracy and difference: Contesting the boundaries of the political. v. 31, p. 120-135.

\section{Notas}

\footnotetext{
i Disponível em:

<https://www.facebook.com/SenadoFederal/photos/a.176982505650946.49197.150311598318037/17953

09367151577/?type=3\&theater > Acesso em: 15/07/2017 e 30/06/2019.

ii Informações disponíveis em:

<https://www12.senado.leg.br/ecidadania/visualizacaomateria?id=129233\&utm_source=midiassociais\&utm_medium=midias-sociais\&utm_campaign=midias-

sociais\&fbclid=IwAR0JuxbydLuPG9uHJWZ1VO9HL81Jnm1hAop8pwAIsHdjrJRi1TO6-N9FWeQ> Acesso em 30/06/2019.

iii Incluindo os discursos considerados estritamente racionais, estritamente emocionais e híbridos. Considerou-se mais de uma forma de argumentação em um mesmo discurso quando foi o caso.

iv Várias justificativas discursivas foram contabilizadas no mesmo discurso, quando foi o caso.
} 